Article

\title{
Structural and Corrosion Study of Uncoated and Zn-Cu Coated Magnesium-Based Alloy
}

\author{
Mehmet Yakup Haciibrahimoğlu ${ }^{1, *}$, Metin Bedir ${ }^{2}$ and Abdulcabbar Yavuz ${ }^{1}$ \\ 1 Metallurgical and Materials Science Engineering Department, Gaziantep University, \\ Gaziantep 27310, Turkey; ayavuz@gantep.edu.tr \\ 2 Department of Engineering Physics, Gaziantep University, Gaziantep 27310, Turkey; bedir@gantep.edu.tr \\ * Correspondence: yakup@gantep.edu.tr; Tel.: +90-342-317-2240
}

Academic Editors: Adem Kurt, Necip Fazil Yilmaz and Halil Ibrahim Kurt

Received: 31 October 2016; Accepted: 14 December 2016; Published: 19 December 2016

\begin{abstract}
Zn}-\mathrm{Cu}$ alloy was deposited onto AZ63 substrate, and the corrosion behaviour of resulting modified electrodes was investigated in $3 \mathrm{wt} \% \mathrm{NaCl}$ solution in comparison with uncoated AZ63. Electrochemical, structural, and morphological study of the coating is presented. SEM images reveal that the surface morphology of the films is uniformly small spherical grain distributions. The XRD patterns illustrate polycrystalline structure and the formation of peaks corresponding to hexagonal close-packed $\varepsilon$-phase of $\mathrm{Zn}$-Cu with various crystallographic orientations. Cyclic voltammetry was used to determine the potential ranges where the various redox processes occur. Linear sweep voltammetry results illustrate that longer exposure of uncoated $\mathrm{AZ63}$ in $\mathrm{NaCl}$ solution produces a greater corrosion potential shift because of the formation of an oxide layer that did not prevent the progression of corrosion attack. The corrosion resistivity of $\mathrm{Zn}-\mathrm{Cu}$ coated AZ63 is approximately two orders of magnitude greater than that of uncoated AZ63.
\end{abstract}

Keywords: magnesium alloys; brass; electrodeposition; XRD; SEM; corrosion

\section{Introduction}

The consumption of magnesium as a non-ferrous alkaline earth metal has been used for transportation (aerospace, automobile), agriculture, chemical, construction, and energy industries, and even in medical applications thanks to its impressive properties, such as castability, weldability, good machinability, rigidity, toughness, and lightness [1]. In comparison with other materials used, the density of magnesium $\left(1.74 \mathrm{~g} / \mathrm{cm}^{3}\right)$ provides an advantage, as it is $35 \%$ lighter than aluminium and four times lighter than steel. Its low density means low inertia, which is also advantageous in rapidly moving components. Through alloying, the physical and chemical performance of pure $\mathrm{Mg}$ can be significantly increased [2]. However, $\mathrm{Mg}$ and $\mathrm{Mg}$-based alloys suffer from a high corrosion rate (typically greater than $3 \mathrm{~mm} /$ year) [3].

As $\mathrm{Mg}$-based alloys have wide range of probable applications, a good joining process of $\mathrm{Mg}$ and Mg-based alloys is required to combine dissimilar materials. The welding interface does not have different materials than the joining components [4]. Although mechanical and microstructural properties of the welding joints of $\mathrm{Mg}$ alloys have been widely studied [5], their corrosion problems have not been overcome. Corrosion phenomena of magnesium alloys is a serious limitation for their potential applications [6]. Specifically, the corrosion rate of magnesium-based alloys is low at atmospheric conditions [7]. Chloride-including media, however, cause a high corrosion rate of magnesium-based alloys $[6,8]$. Hence, the motivation of this paper is to deposit a well-known coating (brass) onto a Mg-based alloy, and to study its corrosion resistivity compared to a Mg-based alloy in $\mathrm{NaCl}$ solution. If the deposition process is successful and the corrosion resistivity of the film is higher than the Mg alloy, then a welding process applied to Mg-based alloys with similar or dissimilar joining 
materials can be covered by a $\mathrm{Zn}-\mathrm{Cu}$ modified electrode [9]. As the general corrosion behaviour of parent and welding nugget regions are the same, the coating of magnesium and welding of magnesium show the same trend $[10,11]$.

The standard potential of $\mathrm{Mg}$ is more negative than any other engineering metal (including coatings) [12]. The corrosion potentials of $\mathrm{Mg}$ and its alloys are as negative as $-2.4 \mathrm{~V}$ vs. normal hydrogen electrode and $-1.7 \mathrm{~V}$ in aqueous solution due to $\mathrm{Mg}(\mathrm{OH})_{2}$ formation [13]. The corrosion mechanism of $\mathrm{Mg}$-based alloys in artificial seawater ( $3 \mathrm{wt} \% \mathrm{NaCl}$ ) as follows. The surface is covered by a partially protective film and then the corrosion of $\mathrm{Mg}$ (anodic reaction) [14] is formed at the breaks in the film as hydrogen liberation occurs with the cathodic reaction. The surface film formed on Mg-based alloys is not protective (not passivated), and the corrosion rate is more than $3 \mathrm{~mm} /$ year in a $3 \mathrm{wt} \% \mathrm{NaCl}$ solution [3]. The type of magnesium corrosion is irregular localised corrosion [15], which spreads laterally across the surface of Mg-based alloys. As the cathodic reaction is hydrogen liberation, there is not much tendency for deep pitting [15]. The production of $\mathrm{OH}^{-}$ions at the cathodic side of the reaction cause an increase in the value of $\mathrm{pH}$ and a decrease in corrosion tendency of $\mathrm{Mg}$-based alloys, which is considered as a self-limiting reaction. The influence of $\mathrm{pH}$ and some ions (sulphates and chlorides) on the corrosion behaviour of pure magnesium was reported by Song et al. [16,17]. Corrosion studies have been conducted for Mg-based alloys by several research groups [18,19]. Among various surface treatments of magnesium alloys against corrosion, alloy coatings were extensively investigated [20]. Zinc-based coatings on Mg-based alloys can enhance corrosion resistivity, as zinc causes passivation [21,22].

$\mathrm{Zn}-\mathrm{Cu}$ (brass) coatings are used for decorative purposes and to protect the substrates from aggressive media, including strong alkaline and acidic environments — environments which result in lifetime and performance reduction [23,24]. Cyanide-based solutions-which are not desirable due to environmental issues-were used as deposition electrolyte for $\mathrm{Zn}-\mathrm{Cu}$ coatings in industry [25,26]. To solve these issues, environmentally-friendly and cyanide-free media including non-aqueous (ionic liquids [27] and deep eutectic solvents [28]) and aqueous media (gluconate [29], EDTA [30,31], mannitol [32], tartrate [33], ammonia [34], and pyrophosphate-based complex solutions [35,36]) have been used for $\mathrm{Zn}-\mathrm{Cu}$ deposition. Specifically, pyrophosphate deposition bath is an environmentally friendly electrolyte [37], and metals/alloys obtained in this electrolyte do not produce their oxide/hydroxide forms [38-41]. As pyrophosphate bath is alkaline $(\mathrm{pH}>9)$, and the corrosion resistivity of zinc coating deposited from alkaline electrolyte is increased, pyrophosphate bath was selected to coat the magnesium-based alloy in this study [42]. The aim of this study was to investigate the structural behaviour and corrosion resistivity of a magnesium-based alloy (AZ63) and Zn-Cu coated AZ63. As the Zn-Cu film was electrodeposited potentiostatically from pyrophosphate media, deposition and dissolution mechanisms of the film were also studied by means of cyclic voltammetry.

\section{Experimental Section}

The commercial composition of the AZ63 alloy was $90.8 \% \mathrm{Mg}, 6.07 \% \mathrm{Al}, 2.79 \% \mathrm{Zn}$, and $0.34 \% \mathrm{Mn}$. The disc-shaped $\mathrm{Mg}$ alloy working electrode substrates having an exposed area $1 \mathrm{~cm}$ in diameter was covered by a molded, compressed, and heated bakelite method. This is a conventional way to obtain the contact area and to isolate other sections of $\mathrm{Mg}$ alloy substrate from the electrolyte. The surface of the substrate was polished with a Struers-Laboforce-3 polishing set. Zn-Cu alloy was grown on the surface of the AZ63 substrates by using a traditional three electrode system. Pt flag and $\mathrm{Ag} / \mathrm{AgCl}$ (saturated $\mathrm{KCl}$ ) were used as working and reference electrodes, respectively. To grow the $\mathrm{Zn}-\mathrm{Cu}$ alloys, the deposition baths were prepared from $0.90 \mathrm{M} \mathrm{K}_{4} \mathrm{P}_{2} \mathrm{O}_{7}$ (Merck, Darmstadt, Germany), $0.15 \mathrm{M}$ $\mathrm{KH}_{2} \mathrm{PO}_{4}$ (Sigma Aldrich, Steinheim, Germany), $0.20 \mathrm{M} \mathrm{ZnSO} 4$ (Sigma Aldrich, Munich, Germany), and $0.02 \mathrm{M} \mathrm{CuSO}_{4}$ (Sigma Aldrich, Munich, Germany) in double-distilled water (pH = 9.2). Films shown in this study were grown by applying $-1.4 \mathrm{~V}$ for $300 \mathrm{~s}$, and all experiments were conducted at room temperature. 
The corrosion resistance measurements of $\mathrm{Mg}$ alloys before and after coating were performed in 3 wt \% aqueous $\mathrm{NaCl}$ solution in the same Pyrex glass cell. In each measurement step, the specimens were ground mechanically with different high sensitive abrasive SiC papers (400, 800, 1200, 1500, 2000, and 3000) and cleaned in distilled water, then finally subjected to hot air drying process.

The quantitative composition analysis of the coatings was examined by a JEOL JSM 6390 LV scanning electron microscope (SEM, JEOL Ltd., Tokyo, Japan) with an energy dispersive spectrometer (EDX, JEOL Ltd., Tokyo, Japan) working at 15-30 kV. Preferential crystal orientations of the deposits on the AZ63 substrate were determined by X-ray diffraction (XRD) analysis, using a Philips PANalytical X'Pert Pro X-ray diffractometer (PANalytical, Almelo, The Netherlands) with $\mathrm{Cu} \mathrm{K} \alpha$ radiation (1.5418 $\AA$ ). The $2 \theta$ diffraction angle range of $30^{\circ}-90^{\circ}$ was recorded at a rate of $0.02^{\circ} 2 \theta / 0.5 \mathrm{~s}$. The crystal phases were identified comparing the acquired $2 \theta$ values and their intensities. The potentiodynamic measurements for cyclic voltammetry and linear sweep voltammetry were examined to obtain the corrosion characteristics of coated and uncoated AZ63.

\section{Results and Discussion}

\subsection{X-ray Diffraction Analysis}

Figure 1 shows typical X-ray diffraction patterns of Zn-Cu deposition on AZ63 substrate obtained from a solution of copper and zinc salts in a potentiostatic process. The experimentally obtained crystal planes (hkl) were compared with the expected values for the phases described in JCPDS.

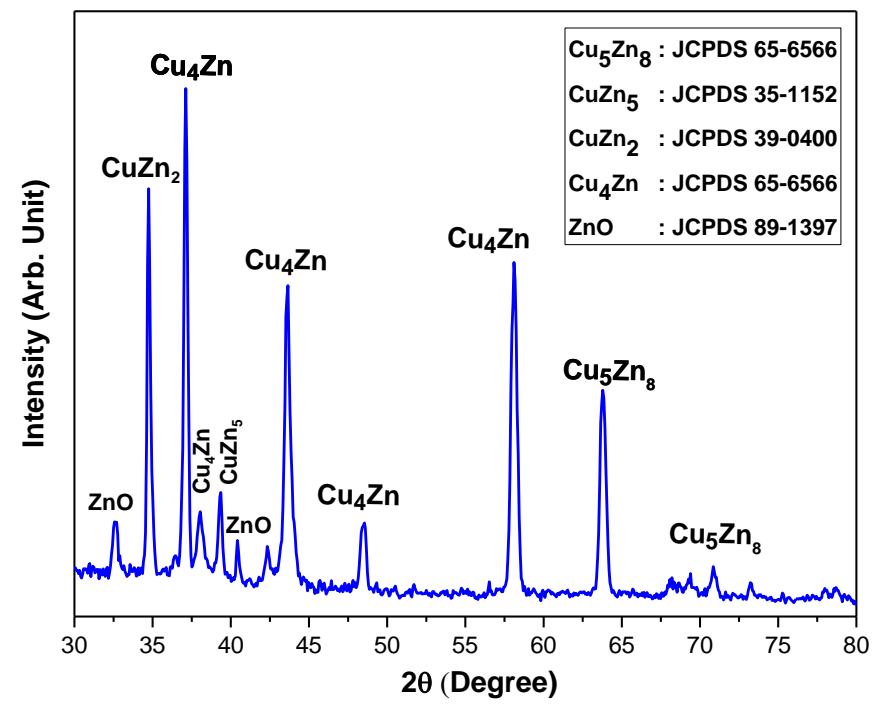

Figure 1. XRD pattern of Zn-Cu alloy growth on AZ63 substrate.

The dominant crystal orientation of the coating depends on the experimental conditions, such as $\mathrm{pH}$, current density, and temperature. The XRD pattern shows the formation of lines corresponding to $\mathrm{ZnO}$ phase, hexagonal close packed $\varepsilon$-phase, and $\mathrm{Zn}-\mathrm{Cu}$ phase, with different crystallographic orientations, and the film has polycrystalline structures. The highest intensity peaks were observed at $2 \theta$ values of $34.74^{\circ}, 37.12^{\circ}, 43.65^{\circ}, 58.10^{\circ}$, and $63.78^{\circ}$. These were well indexed to the planes of $\mathrm{CuZn} \mathrm{n}_{2}$, $\mathrm{Cu}_{0.8} \mathrm{Zn}_{0.2}, \mathrm{Cu}_{0.8} \mathrm{Zn}_{0.2}, \mathrm{Cu}_{0.8} \mathrm{Zn}_{0.2}$, and $\mathrm{Cu}_{5} \mathrm{Zn}_{8}$, respectively. There were also lower intensity peaks observed at the angles $(2 \theta)$ of $32.56^{\circ}, 37.7^{\circ}, 38.9^{\circ}, 41.4^{\circ}, 48.53^{\circ}$, and $72.03^{\circ}$. These were indexed to the planes of $\mathrm{ZnO}, \mathrm{Cu}_{0.8} \mathrm{Zn}_{0.2}, \mathrm{CuZn}{ }_{5}, \mathrm{ZnO}_{1} \mathrm{Cu}_{0.8} \mathrm{Zn}_{0.2}$, and $\mathrm{Cu}_{5} \mathrm{Zn}_{8}$, respectively. The observed phase as expected is based on the binary equilibrium diagram of the $\mathrm{Zn}-\mathrm{Cu}$ system. Figure 1 shows that peaks are generally indexed to the diffractions of intermetallic $\varepsilon$ phase of $\mathrm{Zn}-\mathrm{Cu}$, which is known to have the composition of $\mathrm{Cu}_{0.8} \mathrm{Zn}_{0.2}$. The peak intensity is in planes of hexagonal phase and was observed to be high for $\mathrm{Zn}-\mathrm{Cu}$, which indicates the crystallinity of a $\mathrm{Zn}-\mathrm{Cu}$ alloy. 


\subsection{Scanning Electron Microscope Analysis}

Figure 2 shows the results of the $\mathrm{Zn}-\mathrm{Cu}$ coated AZ63 surface morphology and elemental analysis by means of SEM and EDX. The $\mathrm{Zn}-\mathrm{Cu}$ film-grown from the concentration of $\mathrm{ZnSO}_{4}(0.1 \mathrm{M})$ and that of $\mathrm{CuSO}_{4}(0.01 \mathrm{M})$ in pyrophosphate deposition bath-had $82.9 \mathrm{wt} \% \mathrm{Zn}$ and $17.1 \mathrm{wt} \% \mathrm{Cu}$.
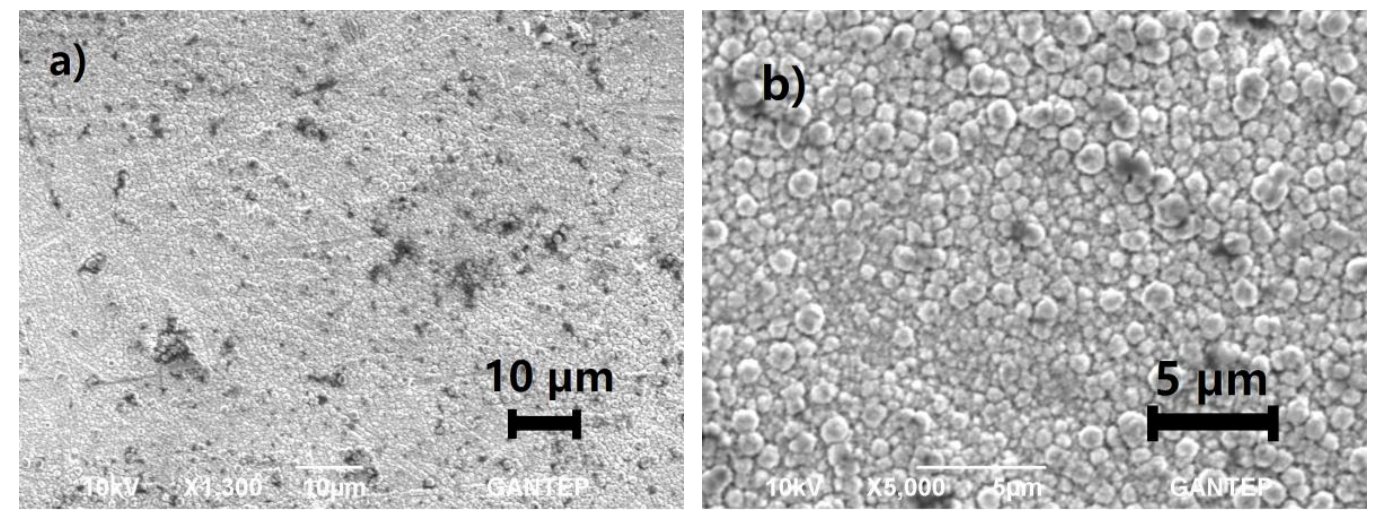

Figure 2. Different magnified SEM images of Zn-Cu coated AZ63 alloy (a) $1300 \times$ and (b) $5000 \times$.

Figure 2a,b shows the different magnified images of $\mathrm{Zn}-\mathrm{Cu}$ coated AZ63. The microstructure of the films consists of different spherical grains distributed uniformly throughout the surface. The intermetallic precipitates have an average diameter between $0.5 \mu \mathrm{m}$ and $2 \mu \mathrm{m}$. As the coating of the precipitate appears compact and uniform, the coating on the matrix appeared uncracked and regular. This is the typical characteristic of a $\mathrm{Zn}-\mathrm{Cu}$ alloy coated surface $[43,44]$.

\subsection{Cyclic Voltammetry Analysis}

The cyclic voltammogram shown in Figure 3 was obtained for AZ63 working electrode in the solution mentioned in the experimental section. The first cathodic peak seen at around $-0.4 \mathrm{~V}$ is attributed to the reduction of $\mathrm{Cu}^{2+}$ to $\mathrm{Cu}^{+}$. Further reduction continuing rapidly at around $-1.3 \mathrm{~V}$ is due to the reduction of $\mathrm{Cu}^{+}$to solid $\mathrm{Cu}$, associated with the reduction of solid $\mathrm{Zn}$ from $\mathrm{Zn}^{2+}$ [45]. The same cyclic voltammograms were obtained from the solution containing zinc and copper electrolyte having a ligand [46]. Indeed, hydrogen evolution also occurs with co-deposition of the $\mathrm{Zn}-\mathrm{Cu}$ alloy [43]. The hydrogen revealed during co-deposition of $\mathrm{Zn}-\mathrm{Cu}$ alloy, however, does not affect $\mathrm{Zn}-\mathrm{Cu}$ composition, as shown in the XRD results.

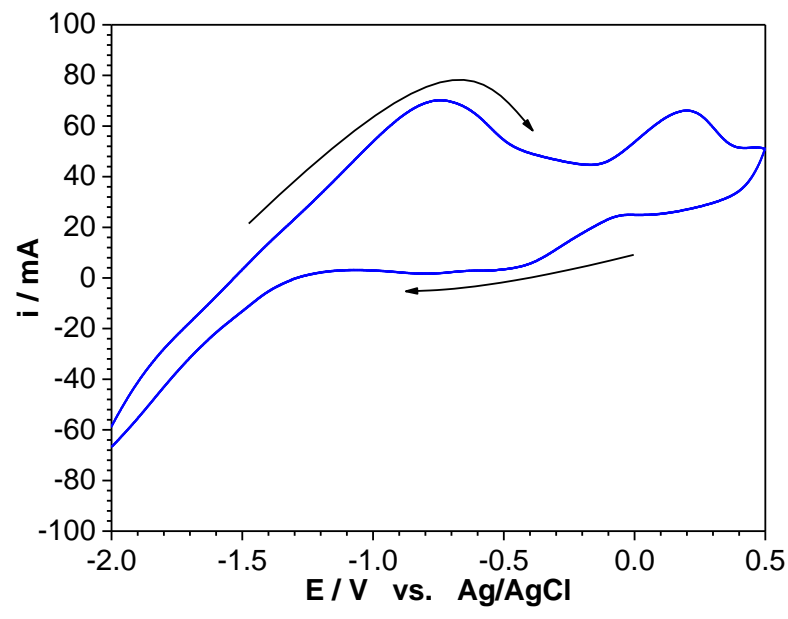

Figure 3. Cyclic voltammogram of AZ63 obtained from electrolytic solution between $-2.0 \mathrm{~V}$ and $+0.5 \mathrm{~V}$ at the scan rate of $100 \mathrm{mV} \cdot \mathrm{s}^{-1}$. 
The film includes various oriented crystals consisting of only $\mathrm{Zn}-\mathrm{Cu}$ alloy (see XRD section). On the reverse direction, the $\mathrm{Zn}-\mathrm{Cu}$ alloy coating is stripped. The peak at around $-0.8 \mathrm{~V}$ is associated to the oxidation of solid $\mathrm{Zn}\left(\mathrm{Zn}^{0}\right)$ to $\mathrm{Zn}^{2+}$ and $\mathrm{Cu}^{0}$ to $\mathrm{Cu}^{+}$. The other oxidation peak at around $0.2 \mathrm{~V}$ appears due to the oxidation of $\mathrm{Cu}^{+}$to $\mathrm{Cu}^{2+}$ [45]. After that potential, the entire $\mathrm{Zn}-\mathrm{Cu}$ alloy is dissolved. Although electrochemically obtained $\mathrm{Zn}-\mathrm{Cu}$ alloy deposition has already been studied [47,48], the work presented here focuses on the corrosion resistivity of the $\mathrm{Zn}-\mathrm{Cu}$ film.

\subsection{Linear Sweep Voltammetry Analyses of Uncoated and Zn-Cu Coated AZ63}

To investigate the corrosion resistivity effect of the coating on AZ63, potentiodynamic anodic and cathodic polarization curves for $\mathrm{Zn}-\mathrm{Cu}$ coated and uncoated AZ63 alloys immersed in a $3 \mathrm{wt} \% \mathrm{NaCl}$ solution for different times are shown in Figure 4.
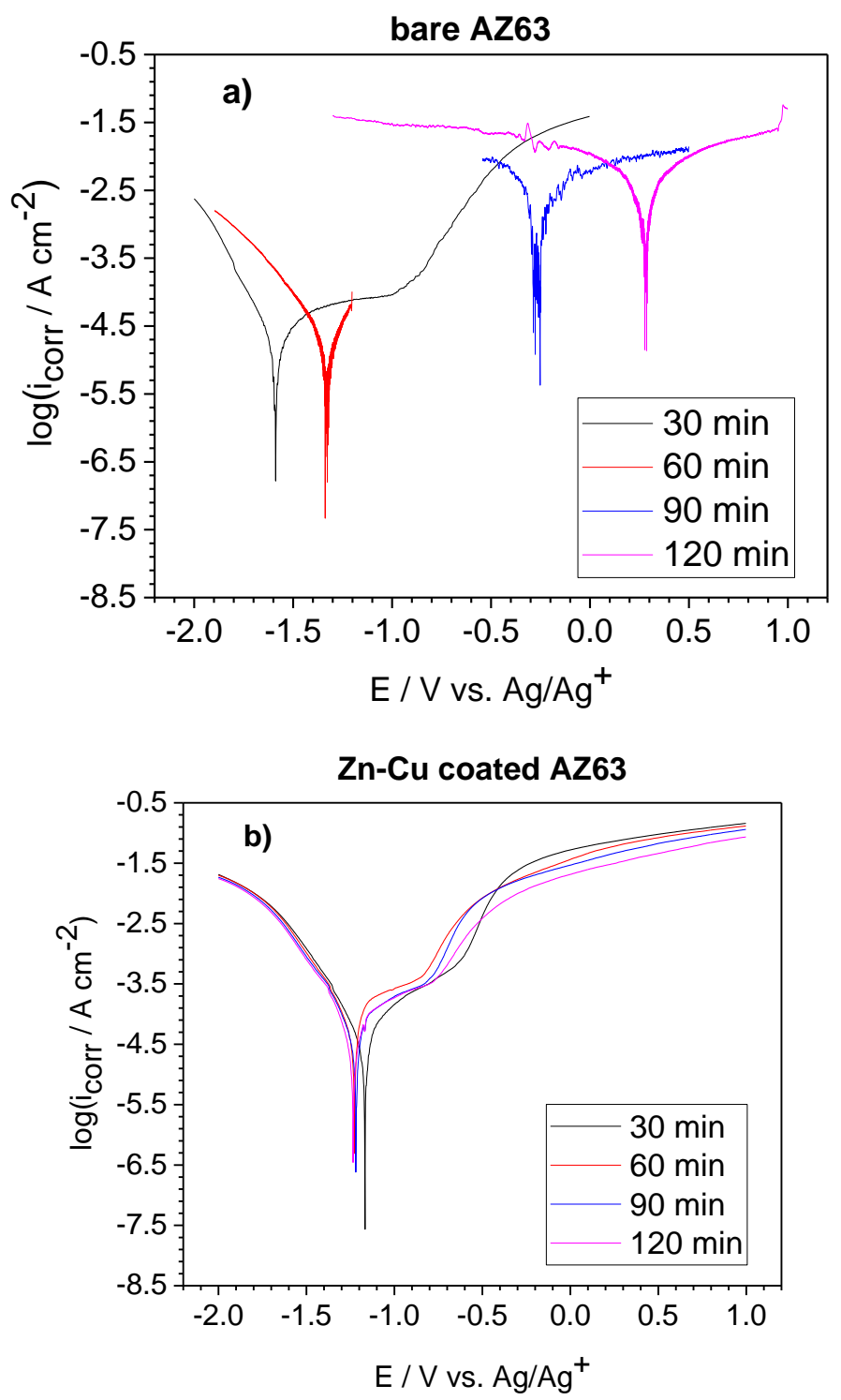

Figure 4. Potentiodynamic polarization curves for (a) uncoated AZ63 alloy and (b) Zn-Cu coated AZ63 in $3 \mathrm{wt} \% \mathrm{NaCl}$ solution for $30,60,90$, and $120 \mathrm{~min}$.

Figure 4a shows that the anodic and cathodic polarisations in the $\mathrm{NaCl}$ solution are affected by the immersion time. Polarization curve of bare AZ63 immersed in $\mathrm{NaCl}$ solution for 30 min can be separated into three distinct regions. The first region is the cathodic polarization commencing 
from $-2.0 \mathrm{~V}$, mainly due to hydrogen evolution. The second region is between $E_{\text {corr }}(-1.6 \mathrm{~V})$ and $-0.9 \mathrm{~V}$, in which there is no significant oxidation of the $\mathrm{Mg}$-based alloy in the corrosive $\mathrm{NaCl}$ medium. However, it is obvious that the bare AZ63 had an oxidised reaction (as expected) in the $\mathrm{NaCl}$ solution after $-0.9 \mathrm{~V}$ in the anodic direction, as the current increases dramatically at this region, corresponding to the third region. The corrosion potential $\left(E_{\text {corr }}\right)$ and the corrosion current density $\left(i_{\text {corr }}\right)$ for all data shown in Figure 4 are given in Table 1. The Tafel plot for the bare AZ63 film immersed in NaCl solution for $60 \mathrm{~min}$ is similar to that for $30 \mathrm{~min}$. However, $E_{\text {corr }}$ and $i_{\text {corr }}$ values for the bare film immersed in $\mathrm{NaCl}$ solution for 90 and $120 \mathrm{~min}$ are significantly changed (see Table 1). The values of polarization resistance $\left(R_{\mathrm{p}}\right)$ given in Table 1 are inversely related to $i_{\text {corr }}$ formulated by the Sterm-Geary equation in terms of the values of anodic $\left(\beta_{\mathrm{a}}\right)$ and cathodic $\left(\beta_{\mathrm{c}}\right)$ Tafel constants [49] (given in Equation (1)).

$$
R_{\mathrm{p}}=\frac{\beta_{\mathrm{c}} \beta_{\mathrm{a}}}{2.3 i_{\text {corr }}\left(\beta_{\mathrm{c}}+\beta_{\mathrm{a}}\right)}
$$

$E_{\text {corr }}$ of the film increases with exposure time due to the formation of a magnesium oxide layer [50]. Additionally, current density increases with exposure time in $\mathrm{NaCl}$. While $i_{\text {corr }}$ of the AZ63 immersed in $\mathrm{NaCl}$ solution for $30 \mathrm{~min}$ is $4.72 \mathrm{~A} \cdot \mathrm{cm}^{-2}, i_{\text {corr }}$ of that for $120 \mathrm{~min}$ is $2.33 \mathrm{~A} \cdot \mathrm{cm}^{-2}$ (from logarithmic calculation, it is 245 times more readily corroded, as $4677 / 19.1=245$, given in Table 1). Increasing in current density with immersion time indicates that the AZ63 film has a pitting corrosion reaction in the $\mathrm{NaCl}$ media.

Table 1. $E_{\text {corr }}$ and $i_{\text {corr }}$ parameters extracted from Tafel plot of Figure 4 in artificial seawater. $R_{\mathrm{p}}$ is calculated from the Sterm-Geary equation.

\begin{tabular}{ccccccc}
\hline \multirow{2}{*}{$\begin{array}{c}\text { Duration in } \\
\mathbf{3} \mathbf{~ w t} \% \mathbf{~ N a C l}\end{array}$} & \multicolumn{3}{c}{ Uncoated AZ63 Alloy } & \multicolumn{3}{c}{ Zn-Cu Coated AZ63 Alloy } \\
\cline { 2 - 6 } & $\boldsymbol{E}_{\text {corr }}(\mathrm{V})$ & $\boldsymbol{i}_{\text {corr }}\left(\boldsymbol{\mu} \mathbf{A} \cdot \mathbf{c m}^{-\mathbf{2}}\right)$ & $\boldsymbol{R}_{\mathbf{p}}\left(\boldsymbol{\Omega} \cdot \mathbf{c m}^{-\mathbf{2}}\right)$ & $\boldsymbol{E}_{\text {corr }}(\mathbf{V})$ & $\boldsymbol{i}_{\text {corr }}\left(\boldsymbol{\mu} \mathbf{A} \cdot \mathbf{c m}^{-\mathbf{2}}\right)$ & $\boldsymbol{R}_{\mathbf{p}}\left(\boldsymbol{\Omega} \cdot \mathbf{c m}^{-\mathbf{2}}\right)$ \\
\hline $30 \mathrm{~min}$ & -1.61 & 19.1 & 4336 & -1.17 & 26.3 & 1791 \\
$60 \mathrm{~min}$ & -1.31 & 26.9 & 1957 & -1.23 & 70.8 & 1082 \\
$90 \mathrm{~min}$ & -0.23 & 2754 & 17.8 & -1.22 & 46.8 & 1664 \\
$120 \mathrm{~min}$ & +0.29 & 4677 & 18.5 & -1.23 & 49.0 & 1663 \\
\hline
\end{tabular}

Figure $4 \mathrm{~b}$ presents the polarisation curves of $\mathrm{Zn}-\mathrm{Cu}$ coated $\mathrm{Mg}$-based alloy at different exposure times in the same corrosive electrolyte ( $3 \mathrm{wt} \%$ aqueous $\mathrm{NaCl}$ solution) used for uncoated AZ63. The values of corrosion potential and corrosion current density for Zn-Cu coated AZ63 are nearly unchanged with different duration. There is a significant shift towards positive potential values from $-1.61 \mathrm{~V}$ to $+0.29 \mathrm{~V}$ (voltage difference is $1.90 \mathrm{~V}$ ) for uncoated AZ63 in $\mathrm{NaCl}$ solution. However, the voltage difference of $\mathrm{Zn}-\mathrm{Cu}$ coated AZ63 between $30 \mathrm{~min}$ and $120 \mathrm{~min}$ is only $0.06 \mathrm{~V}$, meaning that $\mathrm{Zn}-\mathrm{Cu}$ coated AZ63 shows higher resistance than uncoated AZ63 against corrosion. Each polarisation curve of coated AZ63 in $\mathrm{NaCl}$ bath for varied immersion times given in Figure $4 \mathrm{~b}$ has identical oxidation behaviour that is similar to that of uncoated AZ63 in NaCl for 30 min (black line of Figure 4b). The similarity between $\mathrm{Zn}-\mathrm{Cu}$ coated AZ63 curves given Figure $4 \mathrm{~b}$ indicates that $\mathrm{Zn}-\mathrm{Cu}$ coating prevents the pitting corrosion of AZ63.

$i_{\text {corr }}$ for uncoated AZ63 and Zn-Cu coated AZ63 are $4677 \mu \mathrm{A} \cdot \mathrm{cm}^{-2}$ and $49 \mu \mathrm{A} \cdot \mathrm{cm}^{-2}$, respectively. Therefore, the corrosion rate of $\mathrm{Zn}-\mathrm{Cu}$ coating is 96 times less than that of the bare alloy. This difference is due to the passivation and pitting behaviour of the surfaces. Uncoated AZ63 has pitting corrosion. The results of corrosion resistivity calculated from corrosion rate have the opposite trends with polarisation resistance, as expected (see Table 1). When AZ63 is coated with $\mathrm{Zn}-\mathrm{Cu}$, its surface is protected against corrosion, because this protective film creates a barrier between the $\mathrm{Mg}$-based alloy and the corrosive medium during the electrochemical process. The $\mathrm{Zn}-\mathrm{Cu}$ alloy can be simply deposited onto different metals/alloys, including steel [43,45], nickel [51], and copper [52] based materials. If $\mathrm{Mg}$-based alloys are welded (by friction stir welding) to other materials, $\mathrm{Zn}-\mathrm{Cu}$ alloy coating can be deposited onto both dissimilar components and joint to protect them from corrosion. 
The corrosion behaviour of magnesium-based alloys (AZ31 and AZ61) deduced from hydrogen evolution in $0.6 \mathrm{M} \mathrm{NaCl}$ has similar trends as obtained from the electrochemical polarisation data [53].

\section{Conclusions}

In this study, the structural, morphological, and corrosion behaviour of uncoated and $\mathrm{Zn}-\mathrm{Cu}$ alloy-coated AZ63 substrate were investigated. The formation of peaks corresponding to hexagonal close-packed $\varepsilon$-phase of $\mathrm{Zn}$-Cu with different crystallographic orientations were observed, indicating that the film is in a polycrystalline structure. According to microstructural analysis of the films, the surface of coated AZ63 alloy consists of uniformly distributed spherical grains between $0.5 \mu \mathrm{m}$ and $2 \mu \mathrm{m}$ in diameter.

The electroplating behaviour and corrosion characteristics were examined using cyclic and linear sweep voltammetric measurements. There is a significant change in the values of corrosion potential and corrosion current density for uncoated AZ63 in the $\mathrm{NaCl}$ solution. However, the values of $E_{\text {corr }}$ and $i_{\text {corr }}$ for $\mathrm{Zn}-\mathrm{Cu}$ coated AZ63 remain unchanged with different immersion time in $\mathrm{NaCl}$ bath. AZ63 has pitting corrosion reaction in the $\mathrm{NaCl}$ media, and the corrosion is accelerated with immersion time of AZ63 in the chloride-based medium. $\mathrm{Zn}-\mathrm{Cu}$ coating creates a barrier between Mg-based alloy and electrolyte and hence protects AZ63 against corrosion in the corrosive chloride environment. This study suggests that welded Mg-based alloys with similar/dissimilar materials can be protected against corrosion by a $\mathrm{Zn}-\mathrm{Cu}$ coating.

Acknowledgments: This study is supported by University of Gaziantep, Scientific Research Projects Unit (BAPYB) by a research project number of MF.YLT.1608. The Authors would like to thank to Food Products R\&D Centre, Gaziantep University.

Author Contributions: M.Y.H. and M.B. conceived and designed the experiments; M.Y.H. performed the experiments; M.Y.H., M.B. and A.Y. analysed the data; M.Y.H. and A.Y. wrote the paper.

Conflicts of Interest: The authors declare no conflict of interest.

\section{References}

1. Gupta, M.; Sharon, N.M.L. Magnesium, Magnesium Alloys, and Magnesium Composites; John Wiley \& Sons: Somerset, NJ, USA, 2011; pp. 1-11.

2. Forsmark, J.H.; Dowling, Z.; Gibson, K.; Mueller, C.; Godlewski, L.; Zindel, J.; Boileau, J. An investigation of the effects of cast skin on the mechanical properties of an AM60 die-cast magnesium alloy. SAE Int. J. Mater. Manuf. 2015, 8, 714-721. [CrossRef]

3. Candan, S.; Unal, M.; Turkmen, M.; Koc, E.; Turen, Y.; Candan, E. Improvement of mechanical and corrosion properties of magnesium alloy by lead addition. Mater. Sci. Eng. A 2009, 501, 115-118. [CrossRef]

4. Fu, B.; Qin, G.; Li, F.; Meng, X.; Zhang, J.; Wu, C. Friction stir welding process of dissimilar metals of 6061-T6 aluminum alloy to AZ31B magnesium alloy. J. Mater. Process.Technol. 2015, 218, 38-47. [CrossRef]

5. Mishra, R.S.; Ma, Z. Friction stir welding and processing. Mater. Sci. Eng. R Rep. 2005, 50, 1-78. [CrossRef]

6. Song, G.; Atrens, A.; Stjohn, D.; Nairn, J.; Li, Y. The electrochemical corrosion of pure magnesium in $1 \mathrm{~N} \mathrm{NaCl}$. Corros. Sci. 1997, 39, 855-875. [CrossRef]

7. Song, G.L.; Atrens, A. Corrosion mechanisms of magnesium alloys. Adv. Eng. Mater. 1999, 1, 11-33. [CrossRef]

8. Inoue, H.; Sugahara, K.; Yamamoto, A.; Tsubakino, H. Corrosion rate of magnesium and its alloys in buffered chloride solutions. Corros. Sci. 2002, 44, 603-610. [CrossRef]

9. Liu, L.; Ren, D.; Liu, F. A review of dissimilar welding techniques for magnesium alloys to aluminum alloys. Materials 2014, 7, 3735-3757. [CrossRef]

10. Commin, L.; Dumont, M.; Masse, J.E.; Barrallier, L. Friction stir welding of AZ31 magnesium alloy rolled sheets: Influence of processing parameters. Acta Mater. 2009, 57, 326-334. [CrossRef]

11. Laser, T.; Nürnberg, M.R.; Janz, A.; Hartig, C.; Letzig, D.; Schmid-Fetzer, R.; Bormann, R. The influence of manganese on the microstructure and mechanical properties of AZ31 gravity die cast alloys. Acta Mater. 2006, 54, 3033-3041. [CrossRef] 
12. Song, G.; Atrens, A. Understanding magnesium corrosion-A framework for improved alloy performance. Adv. Eng. Mater. 2003, 5, 837-858. [CrossRef]

13. Ambat, R.; Aung, N.N.; Zhou, W. Evaluation of microstructural effects on corrosion behaviour of AZ91D magnesium alloy. Corros. Sci. 2000, 42, 1433-1455. [CrossRef]

14. Thomas, S.; Medhekar, N.; Frankel, G.; Birbilis, N. Corrosion mechanism and hydrogen evolution on Mg. Curr. Opin. Solid State Mater. Sci. 2015, 19, 85-94. [CrossRef]

15. Ročňáková, I.; Montufar, E.B.; Horynová, M.; Zikmund, T.; Novotný, K.; Klakurková, L.; Čelko, L.; Song, G.-L.; Kaiser, J. Assessment of localized corrosion under simulated physiological conditions of magnesium samples with heterogeneous microstructure: Value of X-ray computed micro-tomography platform. Corros. Sci. 2016, 104, 187-196. [CrossRef]

16. Song, G.; Atrens, A.; St. John, D.; Wu, X.; Nairn, J. The anodic dissolution of magnesium in chloride and sulphate solutions. Corros. Sci. 1997, 39, 1981-2004. [CrossRef]

17. Song, G.; Atrens, A.; Wu, X.; Zhang, B. Corrosion behaviour of AZ21, AZ501 and AZ91 in sodium chloride. Corros. Sci. 1998, 40, 1769-1791. [CrossRef]

18. Ambat, R.; Aung, N.N.; Zhou, W. Studies on the influence of chloride ion and $\mathrm{pH}$ on the corrosion and electrochemical behaviour of AZ91D magnesium alloy. J. Appl. Electrochem. 2000, 30, 865-874. [CrossRef]

19. Altun, H.; Sen, S. Studies on the influence of chloride ion concentration and $\mathrm{pH}$ on the corrosion and electrochemical behaviour of AZ63 magnesium alloy. Mater. Des. 2004, 25, 637-643. [CrossRef]

20. Gray, J.; Luan, B. Protective coatings on magnesium and its alloys-A critical review. J. Alloy. Compd. 2002, 336, 88-113. [CrossRef]

21. Song, G.; Johannesson, B.; Hapugoda, S.; StJohn, D. Galvanic corrosion of magnesium alloy AZ91D in contact with an aluminium alloy, steel and zinc. Corros. Sci. 2004, 46, 955-977. [CrossRef]

22. Lian, J.S.; Li, G.Y.; Niu, L.Y.; Gu, C.D.; Jiang, Z.H.; Jiang, Q. Electroless Ni-P deposition plus zinc phosphate coating on AZ91D magnesium alloy. Surf. Coat. Technol. 2006, 200, 5956-5962. [CrossRef]

23. Ebrahimzadeh, M.; Gholami, M.; Momeni, M.; Kosari, A.; Moayed, M.; Davoodi, A. Theoretical and experimental investigations on corrosion control of $65 \mathrm{Cu}-35 \mathrm{Zn}$ brass in nitric acid by two thiophenol derivatives. Appl. Surf. Sci. 2015, 332, 384-392. [CrossRef]

24. Jie, H.; Xu, Q.; Wei, L.; Min, Y. Etching and heating treatment combined approach for superhydrophobic surface on brass substrates and the consequent corrosion resistance. Corros. Sci. 2016, 102, 251-258. [CrossRef]

25. Banerjee, T.; Allmand, A. Experiments on the electrodeposition of brass from cyanide solutions. Trans. Faraday Soc. 1948, 44, 819-833. [CrossRef]

26. Vagramyan, T.; Leach, J.; Moon, J. On the problems of electrodepositing brass from non-cyanide electrolytes. Electrochim. Acta 1979, 24, 231-236. [CrossRef]

27. Schütte, K.; Meyer, H.; Gemel, C.; Barthel, J.; Fischer, R.A.; Janiak, C. Synthesis of Cu, Zn and Cu/Zn brass alloy nanoparticles from metal amidinate precursors in ionic liquids or propylene carbonate with relevance to methanol synthesis. Nanoscale 2014, 6, 3116-3126. [CrossRef] [PubMed]

28. De Vreese, P.; Skoczylas, A.; Matthijs, E.; Fransaer, J.; Binnemans, K. Electrodeposition of copper-zinc alloys from an ionic liquid-like choline acetate electrolyte. Electrochim. Acta 2013, 108, 788-794. [CrossRef]

29. Survila, A.; Mockus, Z.; Kanapeckaitè, S.; Stalnionis, G.; Juškènas, R.; Jasulaitienè, V. Codeposition of zinc and copper in gluconate-sulfate solutions. J. Electrochem. Soc. 2013, 160, D428-D433. [CrossRef]

30. De Almeida, M.R.H.; Barbano, E.P.; Zacarin, M.G.; de Brito, M.M.; Tulio, P.C.; Carlos, I.A. Electrodeposition of cuzn films from free-of-cyanide alkaline baths containing edta as complexing agent. Surf. Coat. Technol. 2016, 287, 103-112. [CrossRef]

31. De Almeida, M.; Barbano, E.; de Carvalho, M.; Carlos, I.; Siqueira, J.; Barbosa, L. Electrodeposition of copper-zinc from an alkaline bath based on edta. Surf. Coat. Technol. 2011, 206, 95-102. [CrossRef]

32. Juškènas, R.; Karpavičienè, V.; Pakštas, V.; Selskis, A.; Kapočius, V. Electrochemical and xrd studies of Cu-Zn coatings electrodeposited in solution with d-mannitol. J. Electroanal. Chem. 2007, 602, 237-244. [CrossRef]

33. Domínguez-Ríos, C.; Moreno, M.; Torres-Sánchez, R.; Antúnez, W.; Aguilar-Elguézabal, A.; González-Hernández, J. Effect of tartrate salt concentration on the morphological characteristics and composition of $\mathrm{Cu}-\mathrm{Zn}$ electroless plating on zamak 5 zinc alloy. Surf. Coat. Technol. 2008, 202, 4848-4854. [CrossRef] 
34. Ibrahim, M.A.; Bakdash, R.S. New cyanide-free ammonia bath for brass alloy coatings on steel substrate by electrodeposition. Int. J. Electrochem. Sci. 2015, 10, 9666-9677.

35. Johannsen, K.; Page, D.; Roy, S. A systematic investigation of current efficiency during brass deposition from a pyrophosphate electrolyte using RDE, RCE, and QCM. Electrochim. Acta 2000, 45, 3691-3702. [CrossRef]

36. De Almeida, M.; Barbano, E.; de Carvalho, M.; Tulio, P.; Carlos, I. Copper-zinc electrodeposition in alkaline-sorbitol medium: Electrochemical studies and structural, morphological and chemical composition characterization. Appl. Surf. Sci. 2015, 333, 13-22. [CrossRef]

37. Kumar, M.P.; Nidhi, M.; Srivastava, C. Electrochemical exfoliation of graphite to produce graphene using tetrasodium pyrophosphate. RSC Adv. 2015, 5, 24846-24852. [CrossRef]

38. Sylla, D.; Savall, C.; Gadouleau, M.; Rebere, C.; Creus, J.; Refait, P. Electrodeposition of Zn-Mn alloys on steel using an alkaline pyrophosphate-based electrolytic bath. Surf. Coat. Technol. 2005, 200, 2137-2145. [CrossRef]

39. Therese, G.H.A.; Kamath, P.V. Electrochemical synthesis of metal oxides and hydroxides. Chem. Mater. 2000, 12, 1195-1204. [CrossRef]

40. Konno, H.; Nagayama, M. Mechanism of electrodeposition of copper from cupric pyrophosphate solutions. Electrochim. Acta 1977, 22, 353-358. [CrossRef]

41. Kravtsov, V.; Kondratiev, V. Kinetics and mechanism of pyrophosphate metal complexes electroreduction. Electrochim. Acta 1991, 36, 427-434. [CrossRef]

42. Narkevicius, A.; Bucinskiene, D.; Samuleviciene, M.; Ramanauskas, R. Corrosion behaviour of Zn coatings electrodeposited from alkaline and acid solutions. Trans. Inst. Met. Finish. 2003, 81, 93-97.

43. Carlos, I.A.; de Almeida, M.R.H. Study of the influence of the polyalcohol sorbitol on the electrodeposition of copper-zinc films from a non-cyanide bath. J. Electroanal. Chem. 2004, 562, 153-159. [CrossRef]

44. El Meguid, E.A.; Awad, N.K. Electrochemical pitting corrosion behaviour of $\alpha$-brass in LiBr containing solutions. Corros. Sci. 2009, 51, 1134-1139. [CrossRef]

45. Haciibrahimoglu, M.Y.; Yavuz, A.; Oztas, M.; Bedir, M. Electrochemical and structural study of zinc-rich brass deposited from pyrophosphate electroyte onto the carbon steel. Dig. J. Nanomater. Biostruct. 2016, 11, 251-262.

46. Ballesteros, J.; Torres-Martínez, L.; Juárez-Ramírez, I.; Trejo, G.; Meas, Y. Study of the electrochemical co-reduction of $\mathrm{Cu}^{2+}$ and $\mathrm{Zn}^{2+}$ ions from an alkaline non-cyanide solution containing glycine. J. Electroanal. Chem. 2014, 727, 104-112. [CrossRef]

47. Zeng, R.-C.; Zhang, J.; Huang, W.-J.; Dietzel, W.; Kainer, K.; Blawert, C.; Wei, K. Review of studies on corrosion of magnesium alloys. Trans. Nonferr. Met. Soc. China 2006, 16, s763-s771. [CrossRef]

48. Pardo, A.; Merino, M.C.; Coy, A.E.; Arrabal, R.; Viejo, F.; Matykina, E. Corrosion behaviour of magnesium/aluminium alloys in 3.5 wt. \% NaCl. Corros. Sci. 2008, 50, 823-834. [CrossRef]

49. Stern, M.; Geary, A.L. Electrochemical polarization I. A theoretical analysis of the shape of polarization curves. J. Electrochem. Soc. 1957, 104, 56-63. [CrossRef]

50. Liang, J.; Srinivasan, P.B.; Blawert, C.; Dietzel, W. Comparison of electrochemical corrosion behaviour of $\mathrm{MgO}$ and $\mathrm{ZrO}_{2}$ coatings on AM50 magnesium alloy formed by plasma electrolytic oxidation. Corros. Sci. 2009, 51, 2483-2492. [CrossRef]

51. Sorensen, C.D.; Nelson, T.W. Friction stir welding of ferrous and nickel alloys. Frict. Stir Weld. Process. 2007. [CrossRef]

52. Lee, W.-B.; Jung, S.-B. The joint properties of copper by friction stir welding. Mater. Lett. 2004, 58, 1041-1046. [CrossRef]

53. Feliu, S.; Samaniego, A.; Barranco, V.; El-Hadad, A.A.; Llorente, I.; Adeva, P. The effect of low temperature heat treatment on surface chemistry and corrosion resistance of commercial magnesium alloys AZ31 and AZ61 in $0.6 \mathrm{M} \mathrm{NaCl}$ solution. Corros. Sci. 2014, 80, 461-472. [CrossRef]

(C) 2016 by the authors; licensee MDPI, Basel, Switzerland. This article is an open access article distributed under the terms and conditions of the Creative Commons Attribution (CC-BY) license (http:/ / creativecommons.org/licenses/by/4.0/). 